\title{
The Effects of Specific Trainings Applied to 14 Age Male Soccer Players on Their Balance, Sprint and Technical Skills
}

\author{
Barış Baydemir ${ }^{1}$, Mahmut Alp ${ }^{2}$ \\ ${ }^{1}$ Department of Coaching Education, Çanakkale Onsekiz Mart University, Çanakkale, Turkey \\ ${ }^{2}$ Department of Physical Education and Sports Education, Süleyman Demirel University, Isparta, Turkey \\ Correspondence: Mahmut Alp, Department of Physical Education and Sports Education, Süleyman Demirel University, \\ Çünür 32260, Isparta, Turkey.
}

Received: July 8, $2018 \quad$ Accepted: August 19, $2018 \quad$ Online Published: August 29, 2018

doi:10.11114/jets.v6i11.3415 URL: https://doi.org/10.11114/jets.v6i11.3415

\begin{abstract}
The aim of this study was to investigate the effects of specific trainings applied to 14 age male soccer players on their balance, sprint and technical skills. 30 male soccer players, who attended the trainings at least 4 years in Çanakkale Beşiktaş Soccer School, joined to the study by having their parents confirm the "Parental Permission Form". Soccer players mean of length was calculated $158.24 \pm 2.98 \mathrm{~cm}$ and mean of weight was calculated $46.37 \pm 3.44 \mathrm{~kg}$. Soccer-specific trainings were applied to the players 12 weeks, 3 days a week, at least 90 minutes a day. Flamingo balance, 30 meters sprint and technical skill tests were applied before and after the training period. Datas were analyzed in statistic package programme by using "Paired t Test". Results were evaluated according to " $p<0.05$ " significance level. Significant differences were found in comparing the tests' results of soccer players $(p<0.05)$. As a result, it can be said that the inclusion of high-intensity deflection exercises instead of the high-rigidity, flat running conditions applied in soccer-specific training has improved the technical skills of 14-year-old footballers and additionally affects their balance and speed performance positively.
\end{abstract}

Keywords: Soccer, balance, sprint, technique

\section{Introduction}

Soccer is the most popular sport in the world, and is played with different genders and age groups at different levels. The participation in football is an efficient way of increasing the activity and fitness levels of children because it requires long and intense physical effort and practice (Koutures and Gregory, 2010). Physiological and physical demands are required for the best performance in all age groups in today's football (adults, young individuals, and teenagers). These physiological and physical demands include high level activities (like sprint, jump, change direction, shoot), medium intensity activities (jogging) and low-level activities (like walking). These demands are affected by the position of the players, their skill levels, playing types, and team tactical strategies (de Villarreal et al., 2015).

When the rate of children and young people to the general population in our country is evaluated, it is considered that the infrastructure of football must be dealt with in detail, and scientific methodology and studies must be conducted in this field. In this respect, football training for children must be conscious, scientific and organized. When the training programs of children and young people, their physical, physiological and mental and psychological growth and maturation processes must be considered (Eniseler, 2009).

The tactical part of football is developing at a fast level. Together with this development, the training and physical condition field plays an extremely important role in football. Time reaction and skills are the most important skills that affect success (Dadic et al., 2014). During the play, players must be more efficient. In this respect, the speed performance has come to the agenda because players change directions very often. Game analyses show that there are frequent sprints during a game, and the most frequent sprints occur in less than 20 meters (Mathisen, 2014).

During a play, 2 and 4-second sprints occur along each 90 second, sprint covers $3 \%$ of the playing time in a game, and during a game, sprints cover $1 \%$ - 11\% distance. Nearly $95 \%$ of the sprints are shorter than $30 \mathrm{~m}$ and $49 \%$ are shorter than $10 \mathrm{~m}$. For this reason, the performance over or below $10 \mathrm{~m}$ and the one in the first step are key indicators of the player potential. In addition, a game included many explosive forces and requires nearly 15 "stealing the ball", 10 
"Headshots", frequent "ball kicks" and speed at various distances (Chelly et al., 2010).

In the light of these data, the purpose of the study was to examine the effect of the specific training programs applied to 14-year-old male footballers on balance, speed, and technical skill features.

\section{Method}

\subsection{Participants}

A total of 30 footballers who attended Çanakkale Beşiktaş Football School for at least 4 years, whose average height was $158.24 \pm 2.98 \mathrm{~cm}$ and average weight was $46.37 \pm 3.44 \mathrm{~kg}$. They joined to the study by having their parents confirm the "Parental Permission Form". We followed the principles outlined in the Declaration of Helsinki.

\subsection{Measures}

\subsubsection{Measurement of Height}

The heights of the footballers were measured by using a measuring tape on bare feet standing flat on the ground, heels joint, knees tense, and body straight position with $1 \mathrm{~mm}$ sensitivity. The values were recorded as centimeter $(\mathrm{cm})$.

\subsubsection{Measurement of Weight}

The body weights of the footballers were measured by using a digital scale with as thin clothing as possible, and by using a digital scale with a sensitivity of $0,001 \mathrm{~kg}$. The values were recorded as kilogram $(\mathrm{kg})$.

\subsubsection{Flamingo Balance Test}

The Flamingo Balance Test was used for the purpose of determining the static balances of the footballers. According to this test, the Study Group were made to stand up on a wooden balance tool that was $50 \mathrm{~cm}$ in length, $4 \mathrm{~cm}$ in height, and $3 \mathrm{~cm}$ in width on dominant foot. The footballers were then made to bend their other knees and retract to their hips and to hold it with their hands on the same side. While the Study Group was in this position, i.e. on balance with one foot, the time was started and the footballers tried to stay in balance during 1minute. When the balance was disrupted (if the footballers left their feet, fall from the wooden balance tool, if any of their bodies touch the ground, etc.), the timer was stopped. When the study group stood up on the balance tool and established their balance again, the timer was started again and the time was measured from the latest time-point. The test continued in this way for one minute. When the time was up, each time the study group tried to establish their balance was counted (after they fell down), and this number was recorded as the score of the study group when the time was up. Low scores meant that the static balance of the footballers was high (Hrysomallis, 2007).

\subsubsection{Speed Test}

The speed performances of the footballers were measured with a photocell chronometer placed between 0-30 $\mathrm{m}$ in grass ground in weather conditions that were windless. Two chances were given to the footballers and the best score was recorded (Hazar and Taşmektepligil, 2008).

\subsubsection{Technique Skill Test}

As the Technique Skill Test, the F- MARC Manual Test Battery (Speed Dribbling Test), which was developed by FIFA in 1997, was applied. This test battery ensures that the speed is evaluated and the coordination with the ball is measured against time. The player starts the ball behind the line with the command "Ready and Go". The measurement was made with photocell and was recorded as "cm".

\subsection{Procedures}

Trainings specific for football were applied to the footballers for 12 weeks (on Mondays, Wednesdays and Fridays), 3 days a week, 90 minutes a day. In 36-unit training sets, the sample training drills given in Table 1 and the load-relax, repeat and set numbers were considered. In unit training, high-intensity direction changes with the ball were included instead of high-intensity running without the ball. The exercises in which there were the ball and opponent players were preferred. The Flamingo balance, speed and technical skills tests were applied to the participants before and after the training period. 

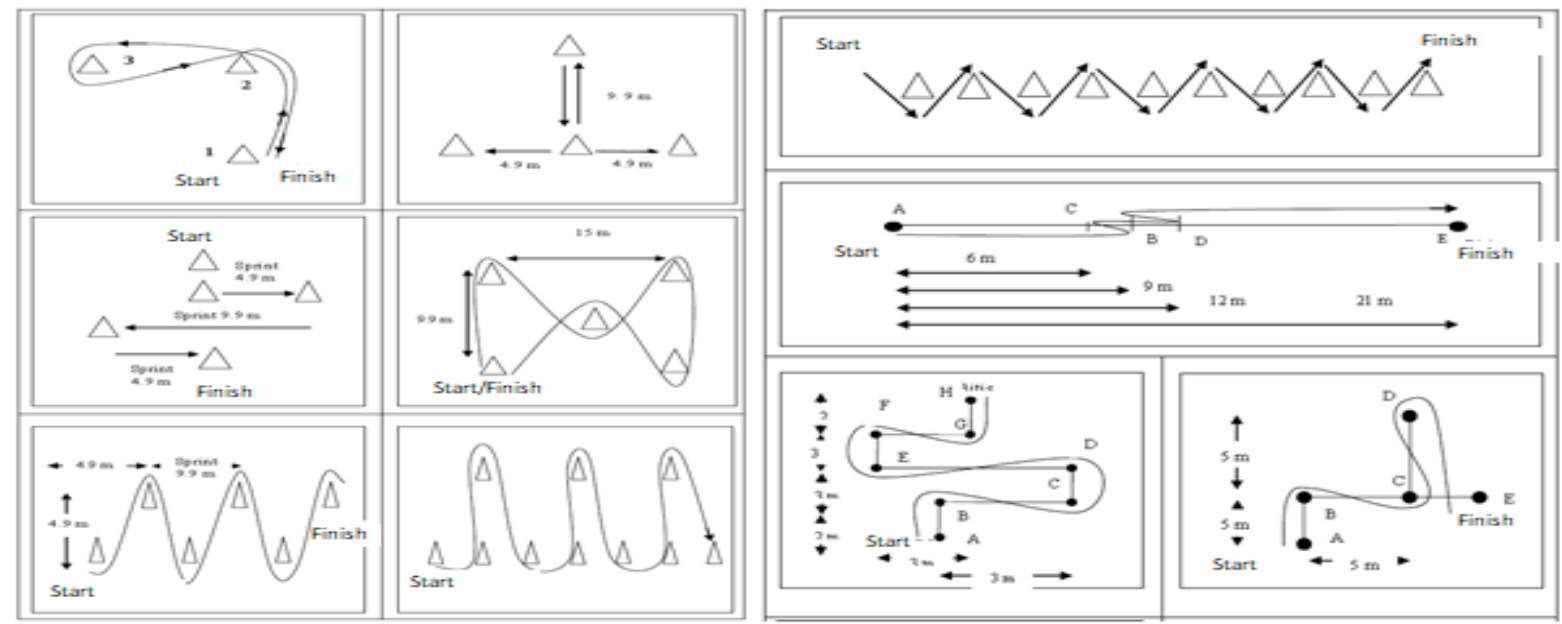

Figure 1. Samples of applied training programs specific for football

Table 1. Training loading parameters

\begin{tabular}{|c|c|}
\hline LOADING METHOD & REPETITIONS \\
\hline Loading intensity and time & $100 \% / 8-10 \mathrm{~s}$ \\
\hline Relaxing time & Full \\
\hline Number of repetitions/interim relaxation & 6-8 s / Full \\
\hline Number of series & $2-3$ \\
\hline Relaxation time between series & $5 \mathrm{~min}$ \\
\hline Number of sets/relaxation time between sets & $2-3 / 5-10 \mathrm{~min}$ \\
\hline
\end{tabular}

\subsection{Statistical Analysis}

The analysis of the data was made in the Statistical Package Program by using the "Paired t-Test" and "Definitive Statistics". The results were evaluated according to " $\mathrm{p}<0.05$ " significance level.

\section{Results}

Table 2. Comparison of Flamingo Balance Pre and Post Test Averages

\begin{tabular}{lccccc}
\hline Balance Test & Test Sequence & Mean & SD & t & p \\
\cline { 1 - 4 } $\begin{array}{l}\text { Flamingo Balance } \\
\text { Test (score) }\end{array}$ & Pre Test & 8.58 & 1.52 & \multirow{2}{*}{11.9} & \multirow{2}{*000}{} \\
\hline
\end{tabular}

When Table 2 was examined, it was found that there was a statistically significant difference between the results of Flamingo Balance pre and post-test averages of footballers.

Table 3. Comparison of $30 \mathrm{~m}$ Speed Pre and Post-Test Average

\begin{tabular}{lccccc}
\hline Sprint Test & Test Sequence & Mean & SD & t & p \\
\hline \multirow{2}{*}{ 30 meters } & Pre Test & 9.11 & .48 & \multirow{2}{*}{7.1} & \multirow{2}{*000}{} \\
\cline { 2 - 4 } & Post Test & 8.52 & .56 & &
\end{tabular}

Table 3 shows that the difference between the pre and post-test averages of $30 \mathrm{~m}$ sprint tests was statistically significant in football players.

Table 4. Comparison of Technical Skill Pre- and Post-Test Averages

\begin{tabular}{lccccc}
\hline Technical Skill Test & Test Sequence & Mean & SD & t & p \\
\hline F-MARC Manual & Pre Test & 23.86 & 2.27 & \multirow{2}{*}{6.4} & \multirow{2000}{*}{ Test (sec) } \\
\cline { 2 - 4 } & Post Test & 22.64 & 2.01 & &
\end{tabular}

As shown in Table 4, it was found statistically difference as a result of comparing the technical skills pre and post-test averages of football players. 


\section{Discussion}

As a result of the study, when the relation between motoric properties of the footballers was evaluated, it was determined that there is a linear significant relation between the balance and speed performances of the footballers as a result of the 8-week training applied to the footballers with high-intensity direction change exercises applied with the ball; in other words, it was determined that the development in the technique skill performances of the footballers affected the balance and speed performances in a positive manner $(\mathrm{p}>0.05)$.

There are studies in the literature examining the effect of specific trainings applied to young footballers on balance development. In a previous study, the core trainings were applied to young footballers for 8 weeks, and a positive difference between the pretest-posttest values at the end of the study (Junge et al., 2000). In another study, positive developments were reported in the balance performances of young footballers as a result of applying force-based specific trainings applied for 8 weeks (Köklü et al., 2015). In another study, it was reported that applying specific trainings for 8 weeks to young footballers affected the balance development in a positive way (Doğan et al., 2016). One study concluded that specific trainings aimed to develop motoric skills in soccer contributed static and dynamic balance of 10-12 age soccer players positively (Tanır 2018).

There are also some other studies examining the speed development of young footballers. In a previous study, trainings were applied three days a week for 10 weeks, and it was determined that there was a significant difference between the speed parameters of the study group and other groups (Markovic et al., 2007). In another study, 8-week trainings were applied to 15-16-year-old footballers, and a significant difference was detected in the study group between the pretest-posttest running times in terms of the speed parameter, and no significant differences were detected in the control group (Kurt et al., 2010). It was reported in the literature that specific trainings applied to players for 8 weeks for speed development caused positive developments between the pretest-posttest scores (An1l et al., 2001; Öztin 2003). When the values obtained in speed development are compared with those reported in previous studies in the literature, it is possible to claim that the results show parallelism.

In previous studies that were conducted on technical skills, on the other hand, there are results that overlap and do not overlap with the results found in the present study of ours. In a study conducted with 30 football player children, significant differences were detected between the pretest-posttest scores in passing the ball, shooting, and driving the ball (Kurban, 2008). In another study conducted on 82 infrastructure football players, the study lasted 10 weeks, and significant differences were detected between the "driving the ball" levels that is specific to football (Pinear and Viljoen, 2010). In another study, the Football Aptitude Test, which was prepared by Portugal Football Federation, was applied to 13-15 age group 69 male footballers, and as a result, it was determined that no significant differences were detected between the passing the ball, shooting, and driving the ball measurements (Malina et al., 2007).

As a result, it is possible to claim that including high-intensity direction changing trainings with the ball instead of high-intensity plain running without the ball in football trainings develops technical skills of 14-year-old footballers, and affect the balance and speed performances in a positive way.

\section{References}

Anıl, F., Erol, E., \& Pulur, A. (2001). The effects of plyometric exercises on phyciological and physical parameters of 14-16 years old female basketball players. Gazi Journal of Physical Education and Sports Sciences, 6(2), 19-26.

Chelly, M. S., Ghenem, M. A., Abid, K., Hermassi, S., Tabka, Z., \& Shephard, R. J. (2010). Effects of in-season short-term plyometric training program on leg power, jump-and sprint performance of soccer players. The Journal of Strength \& Conditioning Research, 24(10), 2670-2676. https://doi.org/10.1519/JSC.0b013e3181e2728f

Dadić, M., Svilar, L., \& Milanović, L. (2014). Effects of plyometric training on explosiveness among junior football players. In 7th International Scientific Conference on Kinesiology (p. 588).

de Villarreal, E. S., Suarez-Arrones, L., Requena, B., Haff, G. G., \& Ferrete, C. (2015). Effects of plyometric and sprint training on physical and technical skill performance in adolescent soccer players. The Journal of Strength \& Conditioning Research, 29(7), 1894-1903. https://doi.org/10.1519/JSC.0000000000000838

Doğan, G., Mendeş, B., Akcan, F., \& Tepe, A. (2016). The Effects of Eight-week Core Training on Some Physical and Physiological Parameters of Football Players. Niğde University Journal of Physical Education and Sport Sciences, $10(1), 1-12$.

Eniseler, N. (2009). Football in children and teens. TFF-FGM Football Training Publications.

Hazar, F., \& Taşmektepligil, Y. (2008). The effects of balance and flexibility on agility in prepuberte period. Spormetre Journal of Physical Education and Sports Sciences, 4(1), 9-12.

Hrysomallis, C. (2007). Relationship between balance ability, training and sports injury risk. Sports medicine, 37(6), 


\section{7-556. https://doi.org/10.2165/00007256-200737060-00007}

Junge, A., Dvorak, J., Rosch, D., Graf-Baumann, T., Chomiak, J., \& Peterson, L. (2000). Psychological and sport-specific characteristics of football players. The American Journal of Sports Medicine, 28(5_suppl), 22-28. https://doi.org/10.1177/28.suppl_5.s-22

Köklü, Y., Alemdaroğlu, U., Özkan, A., Koz, M., \& Ersöz, G. (2015). The relationship between sprint ability, agility and vertical jump performance in young soccer players. Science \& Sports, 30(1), e1-e5. https://doi.org/10.1016/j.scispo.2013.04.006

Koutures, C. G., \& Gregory, A. J. (2010). Injuries in youth soccer pediatrics, 125(2), 410-414.

Kurban, M. (2008). Investigating the effects of basic technical exercises of football on some motoric ability Ph.D Thesis, Selçuk University Institute of Health Sciences.

Kurt, İ., Ağaoğlu, S. A., Ertem, R. N., Akdenk, M., Şişman, H., Özdemir, A., \& Kurt, M. K. (2010). The effect of performance stretch shortening cycle muscle work training program on the speed and agility of 15-16 years old male soccer players. Antalya, 11th International Sport Sciences Congress, 148-151.

Malina, R. M., Ribeiro, B., Aroso, J., \& Cumming, S. P. (2007). Characteristics of youth soccer players 13-15 years classified by skill level. British journal of sports medicine, 41, 290-295. https://doi.org/10.1136/bjsm.2006.031294

Markovic, G., Jukic, I., Milanovic, D., \& Metikos, D. (2007). Effects of sprint and plyometric training on muscle function and athletic performance. The Journal of Strength \& Conditioning Research, 21(2), 543-549.

Mathisen, G. E. (2014). Effect of high-speed and plyometric training for 13-year-old male soccer players on acceleration and agility performance. Lase Journal of Sport Science, 5(2), 3-14. https://doi.org/10.1515/ljss-2016-0027

Öztin, S., Erol, A. E., \& Pulur, A. (2003). The effect of pliometric and explosive power trainings on the physical and physiological characteristics of 15-16 ages group basketball players. Gazi Journal of Physical Education and Sports Sciences, 8(1), 41-52.

Pienaar AE, Viljoen A. (2010). Physicaland motor ability, anthropometrical and growth characteristics of boys in the North West province of South Africa: a sport talent perspective, South African Journal For Research in Sport, Physical Education And Recreation, 32(2), 71-93.

Tanır, H. (2018). The effect of balance and stability workouts on the development of static and dynamic balance in 10-12-year-old soccer players. Journal of Education and Training Studies, 6(9), 132-135. https://doi.org/10.11114/jets.v6i9.3499

\section{Copyrights}

Copyright for this article is retained by the author(s), with first publication rights granted to the journal.

This is an open-access article distributed under the terms and conditions of the Creative Commons Attribution license which permits unrestricted use, distribution, and reproduction in any medium, provided the original work is properly cited. 